\title{
RELACIONAMENTO COM O GOVERNO E INFORMAÇÃO PRIVILEGIADA: O CASO DA JBS NO MERCADO DE CAPITAIS BRASILEIRO
}

\author{
RELATIONSHIP WITH THE GOVERNMENT AND INSIDE INFORMATION: \\ THE JBS CASE IN THE BRAZILIAN CAPITAL MARKET
}

\begin{abstract}
RAUL BEAL PARTYKA
Doutorando em Administração de Empresas pela Escola de Administração de Empresas de São Paulo da Fundação Getúlio Vargas - FGV EAESP

Mestre em Administração pela Universidade do Vale do Itajaí - Univali

Orcid: https://orcid.org/0000-0001-7941-2152 / E-mail: raul.partyka@fgv.edu.br

Rua Itapeva, 474 - 8o Andar, Bela Vista, São Paulo - SP, CEP 01332-000
\end{abstract}

\section{BRUNO BERGMANN}

Professor na Faculdade Borges de Mendonça e Faculdade Cesusc

Mestre em Administração pela Universidade do Vale do Itajaí - Univali

Orcid: https://orcid.org/0000-0002-8158-7303 / E-mail: brunobergmann6@gmail.com

\section{ROSILENE MARCON}

Professora e Coordenadora do PPGA na Universidade do Vale do Itajaí - Univali Doutora em Engenharia da Produção pela Universidade Federal de Santa Catarina - UFSC

Orcid: https://orcid.org/0000-0002-0478-7715 / E-mail: rmarcon@univali.br

Submissão: 06/08/2019. Revisão: 13/05/2020. Aceite: 07/07/2020. Publicação: 03/08/2020.

DOI: http://dx.doi.org/10.22277/rgo.v13i3.5038

\begin{abstract}
RESUMO
Este caso para ensino retrata uma das práticas contra o sistema financeiro, condenada claramente pelas ótimas práticas de governança corporativa. Refere-se à compra de dólares no mercado futuro realizada pela JBS às vésperas da divulgação do diálogo entre Joesley e o expresidente Michel Temer. O objetivo do caso é estimular o debate sobre as práticas de governança corporativa, verificar o relacionamento de empresas e governo, e de que forma essa relação pode afetar o país e como a informação privilegiada causa impactos no mercado financeiro. Os dados sobre a origem, a história da empresa e os dados econômicos foram obtidos por meio do website da companhia, matérias de revistas, livros e sites. O roteiro, os acontecimentos e a reação da economia e do mercado financeiro, são fatos. O presente caso mostra como o governo e as empresas podem se relacionar no Brasil, via alinhamento de interesses, e a partir disso de que forma que as empresas que possuem informação privilegiada impactam no mercado financeiro e na economia do país. Além disso, o caso contribui para o debate de governança corporativa fornecendo mais um caso de companhias abertas e o estreitamento de relações com o governo.
\end{abstract}

Palavras-chave: Informação privilegiada. Mercado de capitais. Governança Corporativa. Caso para ensino. 
Relacionamento com o governo e informação privilegiada: o caso da JBS no mercado de capitais brasileiro

\begin{abstract}
This teaching case portrays one of the practices against the financial system, clearly condemned by the good practices of corporate governance. It refers to the purchase of dollars in the future market held by JBS on the eve of the disclosure of the dialogue between Joesley and ex-president Michel Temer. The purpose of the case is to stimulate the debate about corporate governance practices, verify the relationship between companies and government, and how this relationship can affect the country and how insider information causes impacts on the financial market. Data on origin, company history and economic data were obtained through the company's website, magazine materials, books, and websites. The script, the events and the reaction of the economy and the financial market, are real facts. The present case shows how government and companies can relate in Brazil, through alignment of interests, and from this in that way that companies that have privileged information impact on the financial market and economy of the country. In addition, the case contributes to the corporate governance debate by providing another case of publicly traded companies and closer ties with the government.
\end{abstract}

Keywords: Insider information. Capital market. Corporate governance. Teaching case.

\title{
1 INTRODUÇÃO
}

O caso aborda os temas de informação privilegiada e práticas de governança no mercado financeiro. A informação privilegiada reforça abordar um conceito de Eficiência de Mercado, no qual segundo Fama (1970), a Eficiência de Mercado aponta que o valor de uma ação corresponde de certa forma as informações divulgadas sobre a empresa que fez a emissão dessas ações. Para isso, são necessários que três pontos aconteçam para que ocorra a Eficiência de mercado: a) inexistência de custos de transação para as negociações das ações; b) todas as informações estão divulgadas e sem custo para todos os participantes; c) convergência das expectativas dos investidores em relação às informações atuais disponíveis e a influência sob o atual preço e a formação de preços futuros.

Dentro da economia, autores como Lucas (1978) em sua teoria de expectativas racionais, ou seja, com o olhar voltado para informações à frente, relaciona assim com a Eficiência de Mercado onde os investidores possuem suas decisões baseados nas expectativas futuras da economia, dessa forma com certo grau previsibilidade, eles formam os preços futuros dos ativos. Stiglitz (1981) reforçou a tese de Fama (1970) no qual um mercado é eficiente a partir do momento que ele consegue incorporar um certo grupamento de informações, para que dessa forma consiga precificar os títulos no mercado de capitais. E ainda assim, essas condições de acordo com Fama (1970) e Stiglitz (1981), demonstram que são importantes, mas não indispensáveis. Com elevados custos de transação, ainda assim, não iria impossibilitar que fosse feito novas correções de preços ao passo que possua novas informações, e ainda mesmo assim, o mercado poderá ser eficiente, se considerar um montante considerável de investidores com as informações do mercado.

É importante abordar que os preços dos ativos possuem fatores de informações divulgadas que irão influenciar a sua cotação. De acordo com Salles (1991) as informações sobre preços passados, projeções de lucros, o risco do ativo, os indicadores de análise fundamentalista da empresa, fatores políticos e econômicos terão impacto nessa formação de preços. 
Logo, um ambiente de mercado de capitais no qual se espera que seja eficiente, deduz que essas informações acolham às necessidades legais colocadas, e principalmente que uma nova informação sobre a empresa seja inserida de modo imediato, tendo como principal consequência a precificação do mercado. Assim as informações pertinentes são as que impactam o fluxo de caixa da companhia e aquilo que os investidores esperam, e que, portanto, envolve o procedimento da formação do preço do ativo (PROCIANOY; ANTUNES, 2001).

Assim observando essas explanações teóricas da Eficiência de Mercado, em que o uso de informações privilegiadas e não divulgadas no mercado financeiro para os demais investidores, e permitindo que um grupo de indivíduos possa realizar operações a seu favor, é considerado um meio ilícito para atuar com ações no Brasil.

Por outro lado, o termo "governança corporativa" chegou ao Brasil por volta do final dos anos 1990. Entre as principais iniciativas de estímulo e aperfeiçoamento do modelo de governança estão: a criação do Novo Mercado da Bolsa de Valores de São Paulo, a nova Lei das S.As (Lei 10.303/01) e o Manual de Governança Corporativa da Comissão de Valores Mobiliários (CVM). Desde a década de 1970, leis foram criadas e as empresas buscaram atender às exigências da CVM. O intuito é promover a transparência ao mercado e assim evitar as práticas de informações privilegiadas, especialmente através da Instrução CVM 358/02, com a aplicação de multas e condenação por crimes que feriram os princípios éticos nas operações financeiras.

Para que a empresa tenha mais transparência entre os envolvidos no seu ambiente interno, e para evitar qualquer conflito entre acionistas e diretores ou funcionários da empresa, a Governança Corporativa tem um papel importante na condução das atividades (TRICKER, 2014). Essencialmente, "a governança corporativa lida com as formas pelas quais os que financiam as corporações asseguram-se que vão obter um retorno sobre o seu investimento" (SHLEIFER; VISHNY, 1997, p. 737).

Dentre os objetivos da governança corporativa, Silveira $(2015$, p. 5) demonstra um objetivo interno e outro externo a empresa que são fundamentais para transmitir transparência ao mercado e aos acionistas. Como objetivo de natureza interna tem-se: "reduzir a probabilidade de surpresas negativas decorrentes de ações intencionais ou involuntárias por executivos ou colaboradores". E de natureza externa: "proporcionar elevada transparência para os públicos interno e externo em relação a questões financeiras, impactos não financeiros e perspectivas do negócio". Ainda, de acordo com Silveira (2015), uma empresa que consegue atingir os objetivos da Governança Corporativa permitirá maior geração de confiança perante a todos que participam do ambiente da firma. Dessa forma, com transparência e mais eficiência de condução conseguem atrair mais investimentos e aumentam o seu valor de longo prazo.

É baseado nesses assuntos de informações privilegiadas no mercado financeiro e as práticas de governança corporativa que esse caso para ensino busca explanar os acontecimentos com a JBS, onde um dos sócios, Joesley Batista, atuou com a venda de ações e compra de dólares dias antes da delação envolvendo o então presidente da república Michel Temer. As consequências ocorridas pelo tal fato serão melhor abordadas ao longo do caso. Assim, este trabalho tem como objetivo, prover conhecimento ao aluno sobre um caso de informação privilegiada no mercado financeiro brasileiro, os impactos que pode trazer para o país, os impactos na bolsa de valores e como as práticas de governança corporativa estão conectados a esses assuntos. 
Relacionamento com o governo e informação privilegiada: o caso da JBS no mercado de capitais brasileiro

\section{O INÍCIO DA HISTÓRIA}

No ano de 1953, José Batista Sobrinho, o "Zé Mineiro", abriu uma pequena casa de carnes chamada Casa de Carnes Mineira, em Anápolis, no interior do estado de Goiás. Durante a segunda metade da década de 1950, a partir do ano de 1957, a empresa começou a fornecer carne bovina para os trabalhadores que construíam a futura capital do Brasil, Brasília. A partir do forte crescimento da região do centro-oeste com o advento na nova capital, e do crescimento da empresa, em 1970 a empresa faz a compra do seu primeiro frigorífico e cria a marca Friboi (JBS, 2019).

O nome foi alterado para JBS a partir de 2007, quando houve um salto grande, já sobre a gestão de Joesley, que então abriu capital na bolsa de valores nesse ano, sendo a primeira empresa do setor no Brasil a emitir ações na Bovespa. Nesse mesmo ano, a companhia adquiriu a empresa de carnes Swift nos Estados Unidos e Austrália. (JBS, 2019). A partir de 2007 também foram feitos investimentos de 8 bilhões de reais, através do governo federal, não na forma de empréstimo, mas pela compra de participação acionaria, por intermédio da BNDES Participações, a BNDESPar, braço de investimentos do banco estatal (COSTA; NARCIZO, 2017).

Já em 2008, a JBS comprou a operação de bovinos da Smithfield nos Estados Unidos, e posteriormente em 2009 após a incorporação da Bertin, a JBS torna-se a maior empresa de proteína animal do mundo (JBS, 2019). Ainda no ano de 2009, um outro grande salto foi dado com a compra da Pilgrim's Pride, uma das maiores produtoras de frangos do mundo. Ao longo da década de 2010, a companhia deu continuidade na expansão internacional. Em 2012, no Canadá, com a compra dos ativos da XL Foods. Em 2013, fato importante no mercado brasileiro, com a compra da Seara, quando passou a atuar no mercado de frangos e suínos no Brasil. A participação da empresa no mercado de frangos ainda foi ampliada com a aquisição da operação da Tyson no México e Brasil, da unidade europeia da Moy Park e de suínos da Cargill nos Estados Unidos. $\mathrm{O}$ aperfeiçoamento tecnológico da empresa foi intensificado em 2016 quando a JBS assumiu o controle da Scott Technology, empresa da Nova Zelândia atuante em automação e robótica para produção de alimentos. (JBS, 2019).

Historicamente a empresa teve, a partir da abertura de capital e do envolvimento com o governo, um crescimento exponencial. Este movimento permitiu ampliar suas operações e territórios de atuação. Conexões políticas é um mecanismo associa as empresas ao governo - e vice-versa - em busca de vantagens de mercado (FACCIO, 2006; FISMAN, 2001) e de não mercado (BARON, 1995). Ao perseguirem seus objetivos políticos, as empresas optam por um relacionamento transacional - que envolve interações únicas - ou por um envolvimento relacional - que envolve o fomento de relacionamentos duradouros com os decisores políticos em inúmeras questões políticas, de modo que os contatos e recursos necessários já estejam em vigor sempre que surgirem questões políticas (HILLMAN; HITT, 1999). Neste sentido, as empresas podem otimizar os retornos de seus investimentos (políticos ou não) ao desenvolverem capacidades políticas ao longo do tempo (HOLBURN; ZELNER, 2010).

Ao investir recursos na associação com o governo, as firmas seriam capazes de capturar vantagens competitivas disponibilizadas no mercado pelas decisões governamentais (BARON, 1995; FACCIO, 2006; HILMANN; HITT, 1999). Além disso, a firma pode beneficiar-se não só do aumento do acesso, mas por meio da informação fornecida à empresa pelo representante individual (HILLMAN; ZARDKOOHI; BIERMAN, 1999). 
No entanto, o alinhamento de interesses entre a JBS e o governo ao longo dos anos fez com que tivesse relações que resultariam em crimes contra o sistema financeiro nacional, provocando efeitos colaterais na economia e na confiança do país. A questão das práticas feitas no mercado financeiro pelos controladores da empresa e os efeitos na economia do país ficaram mais evidentes no ano de 2017, com as delações dos executivos da companhia. Sobretudo, a prisão preventiva de Wesley Batista, presidente da JBS, foi a primeira realizada no Brasil pelo crime de insider trading, isso é, o uso de informação privilegiada para obter lucros no mercado financeiro (AFFONSO; SILVA JÚNIOR; MACEDO, 2017).

Tudo começou com a operação Greenfield a qual Joesley era suspeito de corromper fundos de pensão. Na quarta-feira, 17 de maio de 2017, o jornal O Globo começou a publicar trechos da delação dos irmãos Joesley e Wesley Batista, donos da JBS. No dia seguinte veio a público o áudio de uma conversa entre o ex-presidente Michel Temer e Joesley. Temer teria dado aval ao empresário para a compra do silêncio do ex-deputado Eduardo Cunha, preso há sete meses (PEREIRA; RANGEL; BONIN, 2017). Ao longo de pelo menos treze anos, os irmãos Batista, sócios da holding J\&F, pavimentaram com farta distribuição de propinas uma trajetória de sucesso fulminante. (ZALIS, 2017).

Passados 10 anos da abertura de capital da empresa, e do estreitamento das relações entre a JBS e o governo, a participação ao final de 2018, correspondia a 21,3\% do capital total, dada a cotação da época, equivalendo a $R \$$ 6,8 bilhões (GAIER, 2018). A J\&F, holding que controla a JBS, maior empresa de processamento de proteína animal do mundo, comprou o poder e moldou-o segundo sua conveniência, corrompendo todos, em todas as horas e de todos os jeitos (VEJA, 2017). A estrutura societária completa da companhia é ilustrada na Figura 1.

Figura 1 - Estrutura societária da JBS

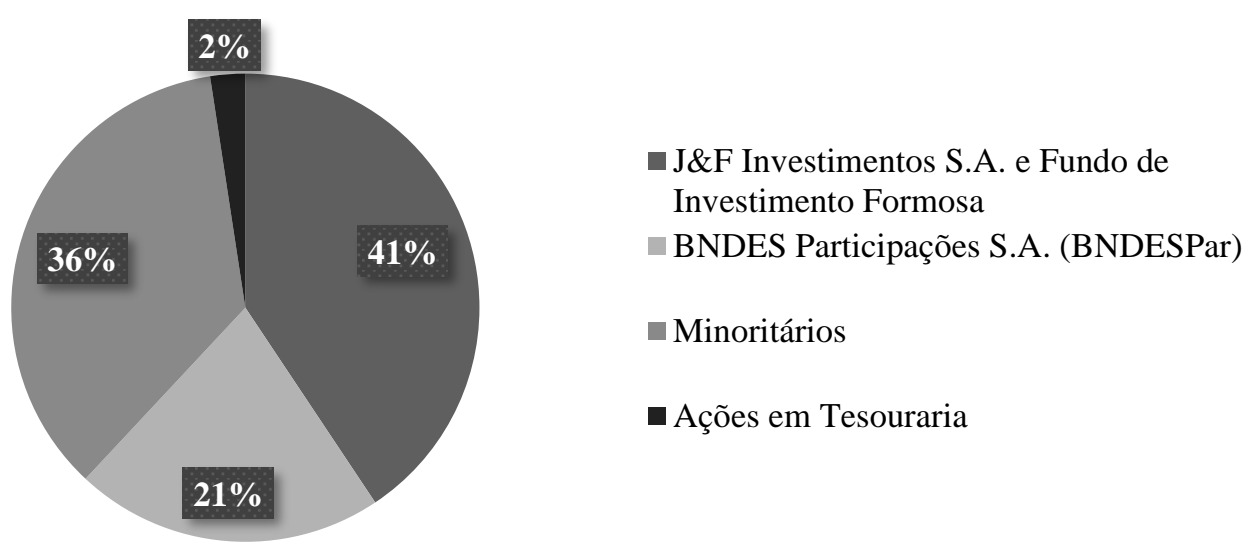

Fonte: JBS (2019).

O faturamento da companhia, em 2016, superou 170 bilhões de reais. Seu crescimento desde 2003, quando Lula assumiu a presidência, foi de $8.900 \%$, até 2016. Nem Warren Buffett ganha tanto em tão pouco tempo. A proximidade com o poder ajudou a companhia também a conseguir o apoio de outros fundos de pensão estatais. Foi com a Funcef, Petros, Previ e Postalis que a J\&F, fundou a Eldorado Celulose. Também financiou via Caixa econômica federal, $100 \%$ dos 2,7 bilhões, para aquisição da Alpargatas em 2015, com carência de dois anos para pagar (COSTA; NARCIZO, 2017). 
Relacionamento com o governo e informação privilegiada: o caso da JBS no mercado de capitais brasileiro

\section{A QUINTA-FEIRA NEGRA}

Parecia que o Brasil ia acabar. Antes mesmo de vir à tona a delação dos executivos da JBS, que estremeceu o país, empresas de Joesley Batista ganharam uma grande quantia apostando na contramão do mercado. Reportagem publicada na Revista VEJA revela que quatro companhias do grupo J\&F, dona da JBS, realizaram quase 3 bilhões de dólares em operações de câmbio e juros - que renderam um ganho de cerca de 600 milhões de reais (BRONZATTO, 2017). Uma das investigações foi instaurada com base na compra de 1 bilhão de dólares, por meio do uso de corretoras, no mercado futuro, no dia 17 de maio de 2017, véspera do vazamento das delações dor irmãos Joesley e Wesley Batista. "Além disso, a companhia adquiriu expressiva quantidade de ações de sua própria emissão (tendo como contraparte sua controladora em grande parte desses negócios) durante o período abrangido pelas investigações conduzidas no âmbito do referido acordo de colaboração com o Ministério Público Federal, pelo que se pode inferir do noticiário político nacional dos últimos dias", relata o procurador da Comissão de Valores Mobiliários Celso Luiz Rocha Serra Filho. (VASSALLO; AFFONSO; MACEDO, 2017).

A Comissão de valores mobiliários (CVM) abriu cinco processos administrativos para averiguar se o grupo J\&F teria se aproveitado de informação privilegiada, o chamado insider trading, para se beneficiar tanto na compra de dólares como na venda de ações da JBS enquanto a delação dos executivos era negociada em abril. (ZALIS, 2017)

Executivos do grupo J\&F sabiam que as suas revelações poderiam surpreender a todos e alterar os rumos do mercado. Por isso, resolveram se antecipar. A própria empresa, que tem negócios no exterior e dívidas atreladas ao dólar, divulgou um comunicado admitindo ter realizado operações com câmbio. Procurado, o BC afirma que não comenta ações de supervisão e nem caso específico. Os detalhes das transações financeiras atípicas também foram enviados pela entidade monetária à Comissão de Valores Mobiliários (CVM), órgão responsável pela fiscalização do mercado de capitais, que já abriu 10 investigações ligadas ao caso JBS.

\section{A BOLSA EM QUEDA}

O Brasil durante o segundo semestre de 2014 até o final do ano de 2016 viveu a maior contração econômica da história republicana, desde que os dados começaram a ser tabulados a partir de 1901. Primeiro veio o desequilíbrio de contas externas, no qual o Brasil saiu de um superávit comercial no ano de 2013 para um déficit comercial no ano de 2014. Os resultados do desequilíbrio de contas externas foram a redução do emprego no Brasil, baixa competitividade das empresas brasileiras e redução da confiança empresarial. Depois teve a inflação, em que o governo federal congelou artificialmente preços de insumos como energia, combustíveis, transportes e demais preços foram corrigidos logo no início de 2015. Como consequência, gerou uma inflação acima do teto da meta de inflação estipulada pelo Conselho Monetário Nacional. (AMORIM, 2016).

Uma nuvem de incertezas voltou a surgir em razão da delação premiada dos donos da empresa de bens de consumo JBS que atingiu o presidente Michel Temer e uma extensa lista de políticos. Logo após as revelações, o lbovespa, principal índice da bolsa de valores brasileira, caiu quase $9 \%$, e o dólar subiu $8 \%$ (ROCHA, 2017). Crise política combina com instabilidade, que gera volatilidade no mercado, e deixa investidores no escuro. Somente 20 minutos após a abertura da Bolsa de Valores de São Paulo os papeis caíram 10,47\%, o que paralisou o pregão. Só em 2008 a 
bolsa brasileira viveu quadro similar, mas era a crise do Lehman Brothers, que afetou o mundo todo (JIMÉNEZ; OLIVEIRA, 2017). Em suma, os resultados foram a maior recessão econômica e forte aumento da taxa de desemprego no país.

Após o processo de impeachment da presidenta Dilma Rousseff em maio de 2016, a posse do vice-presidente Michel Temer, e o aceno para uma agenda que iria buscar o controle de contas públicas, a confiança empresarial acabou aumentando o que ajudou a recuperação econômica, pondo fim à recessão de acordo com a Figura 2.

Figura 2 - Confiança do empresário

\section{Série histórica}

Índice (0 a 100 pontos)*

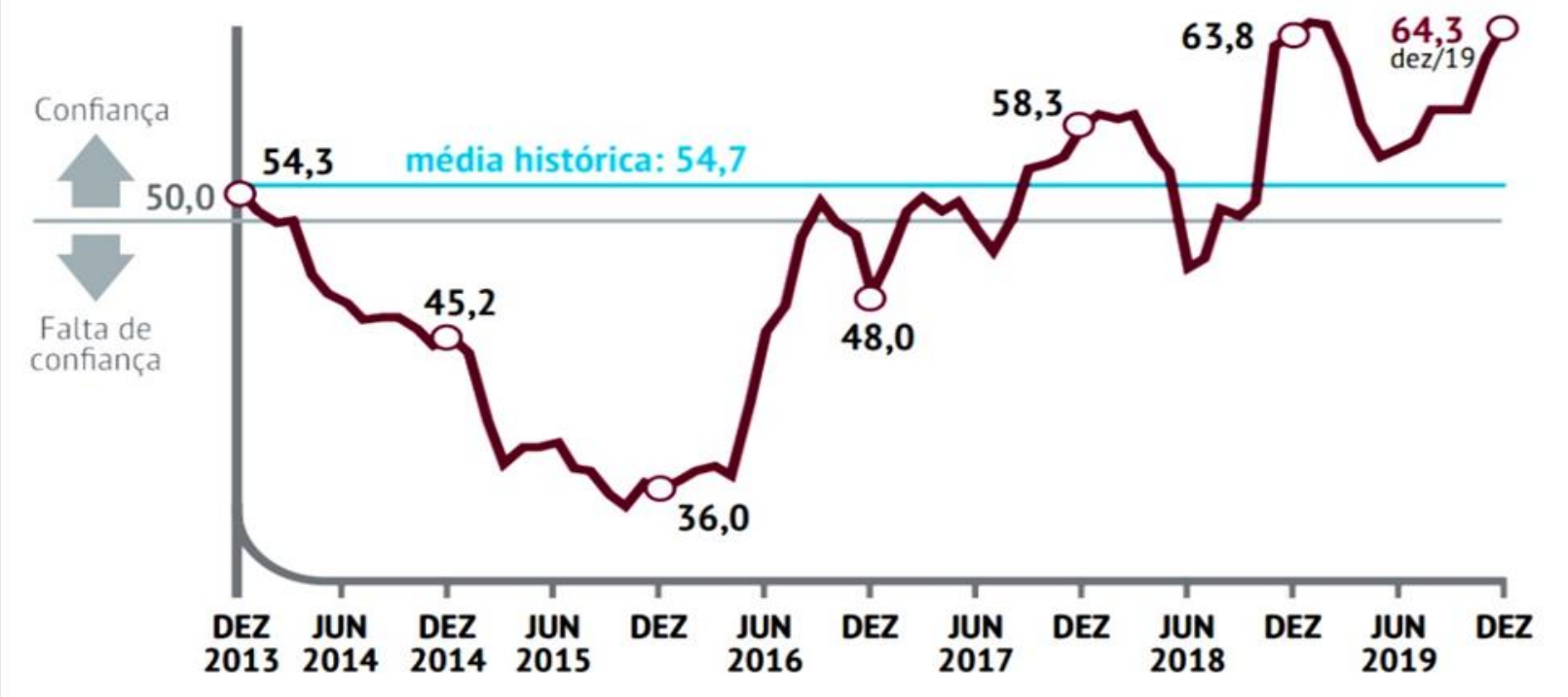

Fonte: CNI (2019).

A economia brasileira estava em recuperação, aumentando seus indicadores de confiança, tendo trimestres de aceleração do crescimento do PIB, redução da taxa de desemprego, até que, conforme a Figura 2, no final do primeiro semestre de 2017, mais especificamente no mês de maio, ocorre a queda da confiança empresarial logo após a delação da JBS.

Portanto, o processo da delação da JBS causou alguns problemas para a recuperação econômica brasileira. De acordo com Saraiva (2017), a delação da empresa causou a redução dos indicadores de confiança do empresário nacional, pois o clima de forte instabilidade política estava retornando ao país. Toda essa instabilidade colocou muitos obstáculos na confiança para investimentos da classe empresarial durante o ano de 2017, o que fez frear a recuperação econômica, o que de fato gerou mais incertezas quanto ao futuro. Além de juros mais baixos, inflação mais fraca e possíveis sinais de retomada na economia, o andamento nas aprovações das reformas agora estariam "paradas", devido ao aumento das incertezas no quadro político.

Os impactos da delação da JBS foram imediatos no mercado financeiro, por essa aversão ao risco, e as instabilidades políticas no Brasil, o país sofreu naquele instante uma fuga de capitais que fez a cotação do dólar subir 8,15\% o preço da moeda americana. (TREVIZAN, 2017). A Figura 2 demonstra outro efeito no mercado financeiro, a queda do índice Ibovespa após a delação. 
Figura 3 - Reação do Ibovespa à delação

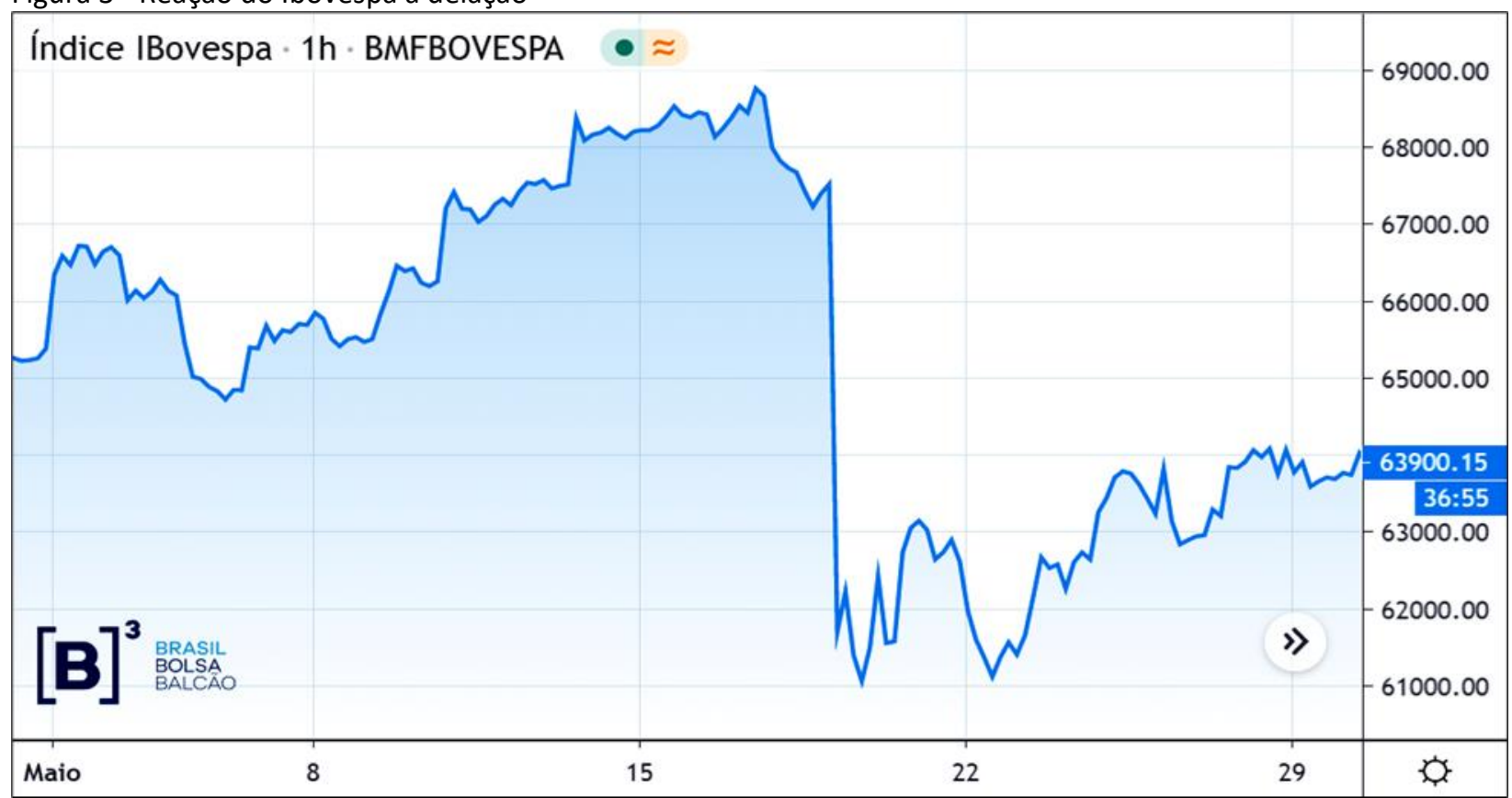

Fonte: B3 (2020).

O índice Ibovespa teve uma queda de 8,8\%. Durante o intraday de negociações na bolsa de valores, foi acionado o circuit breaker de negociações após o índice lbovespa cair 10\% naquele dezoito de maio, algo que então não acontecia desde outubro de $2008 \mathrm{com}$ a crise financeira nos Estados Unidos. A Figura 4 aponta também os efeitos mais específicos das ações da JBS que foram também responsáveis por essa queda no índice Ibovespa.

Figura 4 - Queda da cotação da ação da JBS

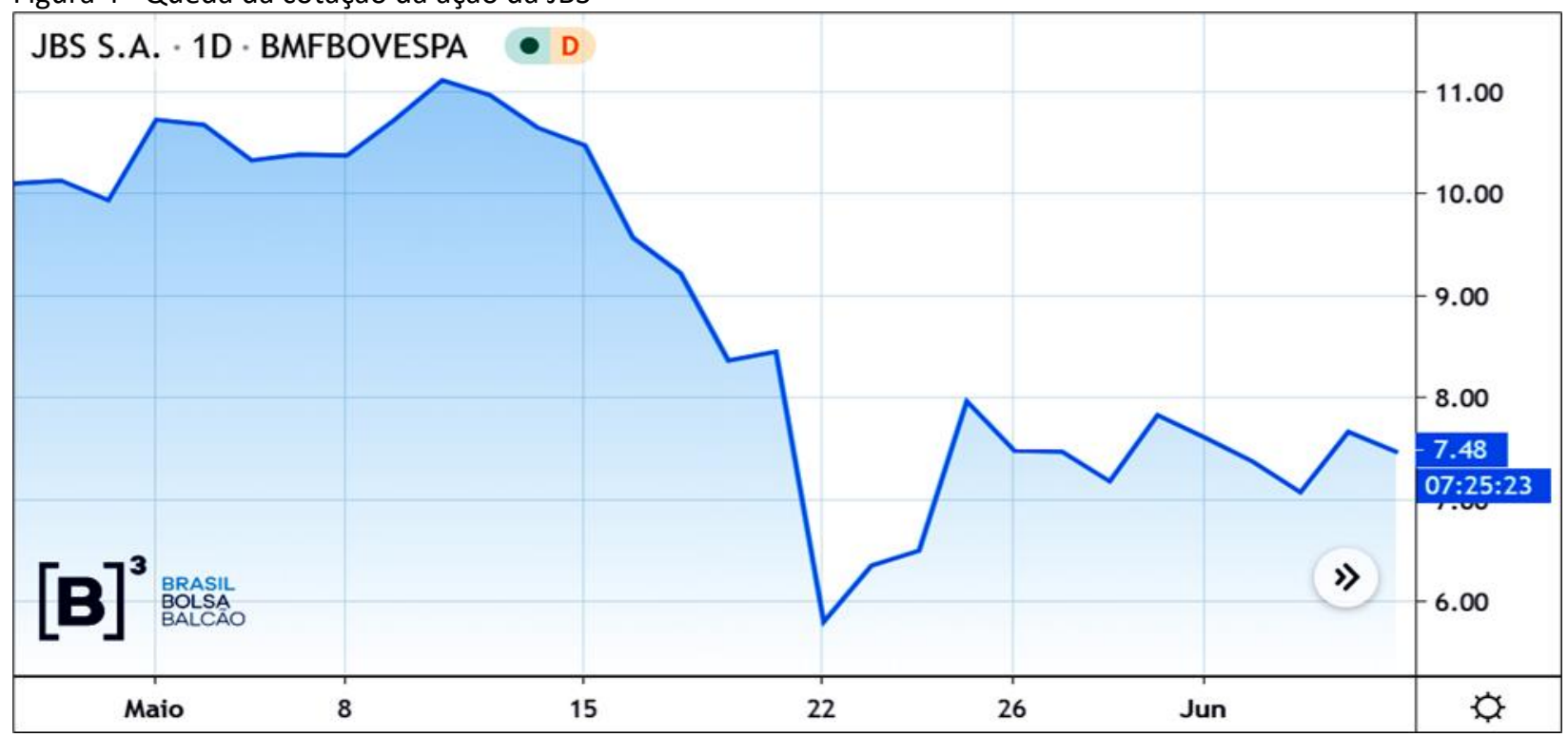

Fonte: B3 (2020).

O papel ordinário da companhia de alimentos amargou queda de 9,68\% na bolsa brasileira, no pregão do dia 18 de maio de 2017 (AZEVEDO, 2017). Conforme até foi previsto pelos 
conselheiros da JBS que utilizaram de informação privilegiada para atuar no mercado em posição de venda das ações em momento anterior a delação, logo após o fato, as ações da JBS tiveram uma queda na cotação na ordem de $44 \%$ nos cinco dias entre 17 e 22 de maio de 2017.

\section{O ACORDO E AS CONSEQUÊNCIAS}

Enquanto Wesley e Joesley foram réus, acusados de ganhos ilegais no mercado financeiro, pelo acordo de delação, homologado pelo Supremo Tribunal Federal (STF), os empresários não passarão um dia se quer na cadeia. Também não precisarão usar tornozeleira eletrônica, nem cumprir pena em regime aberto. Seus bens não serão bloqueados e seus passos não serão vigiados. Em troca, confessar todos os crimes até agora e não cometer novos, e uma multa total de 220 milhões de reais. Qualquer denúncia oferecida será transformada em perdão judicial e nenhuma outra será apresentada. (ZALIS, 2017). Em setembro de 2017, porém, a Procuradoria Geral da República suspendeu os acordos de Joesley Batista e de Ricardo Saud, outro delator do grupo, por suspeita de omissão de informações nos depoimentos - Joesley e Saud foram presos por esse motivo. Wesley Batista, também foi preso, em setembro, por suspeita de usar informações privilegiadas para lucrar no mercado financeiro. (BOMFIM, 2018).

Na realidade, o ganho da JBS com a compra de dólares no dia 17 de maio de 2017, é mais que suficiente para a companhia quitar a multa fechada no âmbito do acordo de leniência. Se a cifra foi de 750 milhões de dólares e há quem diga que chegou a 1 bilhão de dólares, o resultado foi de 170 milhões de dólares, considerando a alta da moeda americana no dia 18 de maio de 2017. Somado a isso tem ainda os mais de 300 milhões de reais em ações que os controladores da JBS venderam no mês anterior. Assim, o total supera, e muito, a multa que foi estipulada em 250 milhões de reais. Sorte da JBS que ganhou com a compra dos dólares, mas azar dos investidores que adquiriram as ações da empresa. (AZEVEDO, 2017).

\section{NOTAS DE ENSINO}

As notas de ensino construídas para este caso são de acesso exclusivo aos docentes. Elas possuem o objetivo de direcionar os objetivos, as estratégias metodológicas e a avaliação do caso.

\section{Fontes de dados}

As fontes dos dados da origem e evolução histórica da empresa, bem como das personalidades envolvidas no caso foram obtidas por meio das páginas de revista de circulação nacional e internacional (tais como Exame, El País, Valor Econômico, O Estado de S. Paulo, VEJA, Reuters, entre outras) matéria de revistas de grande circulação e website da companhia em questão. Os dados apresentados no caso os desdobramentos são reais e foram obtidos de fontes secundárias, por meio de reportagens em revistas, páginas da internet, Políticas, Estatuto e Regimentos da Companhia. Inclui-se como principais fontes de informação para construção da história, as revistas Veja e Valor Econômico.

\section{Objetivos educacionais}

O caso foi elaborado com o objetivo de proporcionar o conhecimento acerca da governança corporativa e, mais especificamente da informação privilegiada, em meio a um problema de governança na JBS. 
Relacionamento com o governo e informação privilegiada: o caso da JBS no mercado de capitais brasileiro

- A tomada de decisão deve ser embasada em dois pontos de vista: o da empresa e o do governo como acionista. Pelo lado da empresa, o Conselho de Administração e Diretoria como partes que desejam se conectar ao governo para obter benefícios e tentar barrar legislações indesejadas.

- No ponto de vista do acionista, o governo que investiu reservas públicas e confiou naquela companhia, ao definir o retorno esperado e de reconhecimento nacional e internacional para justificar tal investimento.

- A ênfase didática é voltada a estratégia política, governança corporativa, e finanças, onde o risco é soberano. Sobretudo, focada em verificar até onde o relacionamento entre empresas e governo é interessante, com base na história expressa no caso.

- Ainda, de que forma a conexão política entre governo e empresa, ambos interessados neste relacionamento, pode afetar o país, a política e economia, além da informação privilegiada e seus impactos no mercado financeiro.

\section{Utilização do Caso}

O caso pode ser utilizado para discussão em cursos de graduação e pós-graduação e/ou MBA em Administração de Empresas e Mercado de Capitais, especialmente em disciplinas cujos conteúdos se relacionem com Governança Corporativa e mais especificamente na abordagem sobre informação privilegiada. Os alunos são convidados a ficarem no lugar, por um lado, dos Diretores de uma empresa global, e por outro lado, de um acionista desta companhia. Antes da discussão do caso, recomenda-se a leitura das Fontes de Dados na íntegra e das obras em referências.

\section{Plano de aula sugerido}

Antes de iniciar o plano de aula sugerido ou aquele desenvolvido pelo docente, recomenda-se a leitura na íntegra do caso. Em turmas que já possuem conhecimento prévio nos temas aqui abordados, o docente pode instruir que a leitura seja feita não presencialmente, utilizando o tempo de aula especialmente para a discussão do caso e das questões propostas.

O professor poderá utilizar as divergentes ideias para criar uma discussão sobre as variadas interpretações que podem ser feitas durante a atividade. O Quadro 1 mostra o tempo sugerido para cada atividade.

Quadro 1 - Plano de aula sugerido

\begin{tabular}{|c|l|}
\hline $\begin{array}{c}\text { Tempo } \\
\text { estimado }\end{array}$ & \multicolumn{1}{c|}{ Questões } \\
\hline 0-15 min & Apresentação geral do caso, detalhando seus objetivos \\
\hline 30-40min & Discussão sobre as consequências no contexto do ocorrido para a empresa e para o governo. \\
\hline 60-90min & $\begin{array}{l}\text { 1) Formação de minigrupos, com cada temática abordada no caso e levantamento de } \\
\text { soluções ou alternativas para estancamento do problema em cada tema. Estes minigrupos, } \\
\text { devem ser criados no mínimo 2, onde possa indicar um grupo sendo favorável a todas as } \\
\text { questões, e outro desfavorável. } \\
\text { 2) Ainda, a classe pode ser dividida em dois grandes grupos, e a discussão trabalhada entre o } \\
\text { grupo que representará os shareholders (acionistas) e o outro representando os stakeholders } \\
\text { (sociedade, comunidade, entre outros). }\end{array}$ \\
\hline 20-30min & Fechamento da aula com as devidas tomadas de decisão a partir de então. \\
\hline
\end{tabular}

Fonte: Elaborado pelos autores (2020). 
Questões sugeridas ao professor para discussão em aula

As questões apresentadas a seguir podem ser utilizadas para atingir o objetivo educacional informado, utilizando a discussão dos eixos temáticos por completo ou em separado.

\section{1) Questões sobre Conexões Políticas}

a) De que forma o governo participou dos projetos da JBS?

b) Porque o governo estava ajudando uma grande empresa, pagando juros maiores e emprestando com menores juros? Quais os resultados para a empresa e para o governo durante o período de aproximação de relações até a data da delação?

\section{2) Questões sobre Governança Corporativa}

a) Apresente e comente sobre: qual a prática ilegal executada pelo conselheiro da companhia?

b) Como os fatos do caso estão relacionados com os fenômenos da seleção adversa e do risco moral, sob a luz da Teoria da Agência?

c) Diante dos fatos ocorridos, como foram as reações no mercado financeiro e as perspectivas para a economia do país?

\section{Análise do Caso}

Esta seção tem como objetivo orientar o docente para a resolução das questões sugeridas, bem como, aplicar as teorias e práticas identificadas na construção do caso, que podem nortear a construção do conhecimento. O eixo inicial de perguntas, está baseado nas conexões políticas entre empresa e governo. Já o segundo eixo, o da governança corporativa, foca nas ótimas práticas de governança e a teoria da agência.

\section{Eixo 1) Questões sobre Conexões Políticas}

\section{a) De que forma o governo participou dos projetos da JBS?}

A partir do ano de 2007 quando a empresa JBS já estava com seu capital aberto na bolsa de valores, o governo federal começou a realizar investimentos da empresa na ordem de 8 bilhões de reais, por meio de compra de participação acionária, por intermédio da BNDES Participações, a BNDESPar, um braço de investimentos do governo federal. Esses investimentos tinham como característica a política de investimentos das chamadas campeões nacionais pelo BNDES, e tinham como objetivo o financiamento para internacionalização de grupos brasileiros. No ano de 2017, portanto, 10 anos depois do início dos investimentos federais na empresa, o tamanho do capital total controlado pela BNDESPar corresponde a $21 \%$ do valor total.

O relacionamento entre empresas e governo é algo que tem sido abordado dentro da literatura por meio da atividade política corporativa (do inglês, corporate political activity (CPA)). Como exemplos do uso da CPA, Gundlach, Root e Murphy (1992), apontam as entidades de recebimento de contribuições de campanha nos Estados Unidos, e em troca disso, as empresas buscam entrada em novos mercados, reafirmação da autonomia e da viabilidade da empresa no mercado atual, além da criação de barreiras para novos entrantes e mais facilidade para novos negócios. Um exemplo prático da utilização da CPA pela JBS foram as doações para as campanhas eleitorais e aportes via BNDES na empresa. Como meio de troca desse envolvimento e estreitamento de relações da empresa com o governo, o BNDESPar através das políticas das 
Relacionamento com o governo e informação privilegiada: o caso da JBS no mercado de capitais brasileiro

campeãs nacionais realizou investimentos na empresa com a finalidade de promoção internacional e conquista de novos mercados.

b) Porque o governo estava ajudando uma grande empresa, pagando juros maiores $e$ emprestando com menores juros? Quais os resultados para a empresa e para o governo durante o período de aproximação de relações até a data da delação?

Uma das maneiras utilizadas que as empresas buscam atuar para o seu crescimento não é somente na área comercial, mas também como aponta Getz (1997), existe uma estratégia da empresa na área governamental, onde se encontra a CPA. A partir da abertura de capital da empresa JBS, iniciou-se um processo de alinhamento de interesses entre a empresa e o governo, no qual as doações em campanha acabaram retornando para a companhia em forma de investimentos e créditos subsidiados do BNDES para os projetos da JBS.

\section{2) Questões sobre Governança Corporativa}

a) Apresente e comente sobre: qual a prática ilegal executada pelo conselheiro da companhia?

No mercado financeiro brasileiro, de acordo com Martins, Paulo e Albuquerque (2012), por meio da lei no 10303/2001, o uso indevido de informação privilegiada no mercado de ações é considerado um crime. O uso de informação privilegiada no mercado financeiro pode trazer distorções dos preços, falta de transparência no mercado de ações e problemas relacionados à assimetria de informações (MARTINS; PAULO; ALBUQUERQUE, 2012).

Dessa forma utilizando das informações privilegiadas, os executivos da JBS ao realizarem a delação e divulgação das conversas com o presidente Temer, sabiam que o efeito no mercado financeiro seria de queda das ações na bolsa de valores, e em vista disso, os controladores realizaram em um mês antes a venda de mais de $\mathrm{R} \$ 300$ milhões em ações da empresa, além de uma operação com dólar, em que um dia antes da delação, os executivos realizaram operações em dólares na ordem de 3 bilhões de reais, obtendo um ganho de cerca de 600 milhões de reais em um movimento de informação privilegiada considerado assim então pelo Banco Central.

b) Como os fatos do caso estão relacionados com os fenômenos da seleção adversa e do risco moral, sob a luz da Teoria da Agência?

A Teoria da Agência está preocupada com a resolução de dois problemas que podem ocorrer em relações de agência (EISENHARDT, 1989):

i) Problema de agência que surge quando: os desejos ou objetivos do principal e agente de conflitos e quando é difícil ou caro para o principal para verificar o que o agente está realmente fazendo.

ii) O problema da partilha do risco que surge quando o principal e agente têm atitudes diferentes em relação ao risco

Pelo lado positivista, identifica-se uma política ou comportamento em que acionistas e gestor divergem e, em seguida, evidenciam que os sistemas de informação ou incentivos baseados em resultados resolver o problema de agência. Alternativas para resolver o contrato. 
(JENSEN; MECKLING, 1976). Já o objetivo da literatura principal-agente está em determinar o contrato ótimo, comportamento versus resultado. Agentes, que são incapazes de diversificar seu emprego, devem ser avessos ao risco e diretores, que são capazes de diversificar seus investimentos, deve ser neutro ao risco) (EISENHARDT, 1989).

No caso descrito temos a relação em que:

Principal: é o Governo (devido a participação via BNDESPar)

Agente: a JBS (seus diretores)

Deste relacionamento, surgem dois problemas contratuais:

Risco moral (moral hazard): refere-se a falta de esforço por parte do agente. Não apresentar o esforço acordado.

Seleção adversa: o agente pode alegar ter certas habilidades ou habilidades quando ele é contratado. Surge porque o principal não pode verificar completamente essas habilidades ou habilidades

Para o contexto entre JBS e governo temos:

JBS e risco moral: o agente fugiu do acordado. Os gestores da empresa atuaram "por fora", tentando lucrar (sabendo do quanto aquilo iria impactar, e como poderiam se beneficiar) e o governo como principal ficou sozinho na jogada, sem conhecer o que o agente estava fazendo (tramando), e perdeu muito dinheiro por ter participação acionária.

JBS e seleção adversa: quando o governo financiou, via participação BNDESPAR, acreditava nas habilidades e potenciais dos gestores da JBS, mas, não totalmente. Portanto, o principal não conseguiu capturar esse provável comportamento do agente, em que iria deixar de agir com as habilidades esperadas.

Além disso, por ser uma companhia de capital aberto, não só o governo, mas há influência dos acionistas de forma geral. Em regra, teoria da agência prevê que os gestores de risco-neutro são propensos a escolher a opção "fazer" (contrato baseado em comportamento), enquanto executivos avessos ao risco são susceptíveis de escolha "comprar" (contrato baseada em resultados). Como desdobramento, para o caso da JBS, envolto na primeira opção, pode-se avaliar também pela lente da estrutura de propriedade, um mecanismo de governança, através a participação do governo como acionista.

Hoje a teoria da agência não é só essa interna principal $x$ agente. Mas qualquer relação dependente. Mesmo principal-principal. O conflito é entre estruturas internas, mas a forma que irá ser monitorado pode ocorrer pelos mecanismos externos. Isso demonstra mais uma pressão sobre os gestores, que muitas vezes pode conflitar com os demais acionistas, gerando também o problema principal-principal. O importante, caso o docente opte também por este caminho, é mostrar que a estrutura de propriedade é um instrumento de governança, quando formada por diferentes tipos de investidores, pois tende não criar expropriação. 
Relacionamento com o governo e informação privilegiada: o caso da JBS no mercado de capitais brasileiro

c) Diante dos fatos ocorridos, como foram as reações no mercado financeiro e as perspectivas para a economia do país?

O Brasil durante o segundo semestre de 2014 até o final do ano de 2016 viveu a maior contração econômica da história republicana, desde que os dados começaram a ser tabulados a partir de 1901 (Amorim, 2016). Algo que é importante para a retomada do crescimento econômico em países que passaram por crises econômicas são as expectativas racionais dos agentes econômicos e também a confiança que os mesmos depositam nos atores responsáveis por realizar as políticas econômicas no país possam assim fazer com que a atividade econômica retorne para o processo de crescimento Ainda, quando os agentes econômicos possuem confiança nos atores formuladores de política econômica e as expectativas para o país são favoráveis, os níveis de investimento e consumo aumentam evitando assim uma recessão econômica. (BLANCHARD, 2007).

Dado que o Brasil estava passando por uma forte contração do PIB entre 2014-2016, a partir do momento em que ocorre uma mudança política no comando do país, a confiança empresarial acabou aumentando, o que foi suavizando os efeitos da recessão. A partir do momento em que foi divulgada a delação da JBS o que poderia gerar mais um desgaste político de transição e incertezas no país, o ritmo da retomada do crescimento econômico acabou diminuindo, o país sofreu nos dias após a delação fuga de capitais, e dentro da bolsa de valores, a crise política fez com que fosse acionado o circuit breaker de negociações após o índice lbovespa cair 10\% naquele 18 de maio de 2017, algo que então não acontecia desde outubro de 2008 com a crise financeira nos Estados Unidos.

\section{REFERÊNCIAS}

AFFONSO, J.; SILVA JÚNIOR, A. S.; MACEDO, F. Prisão é a 1ạ por informação privilegiada no Brasil. O Estado de S. Paulo, 14 set. 2017. Recuperado em 20 de janeiro, 2019 de https://economia.estadao.com.br/noticias/geral,prisao-e-a-1-por-informacao-privilegiada-nobrasil,70001994705

AMORIM, R. Depois da tempestade, São Paulo: Prata Editora, 2016.

AZEVEDO, R. CVM abre processo para investigar compra de dólares pela JBS. Revista VEJA, 19 de maio, 2017. Recuperado em 14 de janeiro, 2019 de https://veja.abril.com.br/blog/reinaldo/cvm-abre-processo-para-investigar-compra-de-dolarespela-jbs/

B3. Cotações Índices e Ações. Recuperado em 25 de maio, 2020 de http://www.b3.com.br/pt_br/market-data-e-indices/servicos-de-dados/market-data/cotacoes/

BARON, D. P. The Nonmarket Strategy System. MIT Sloan Management Review, v. 37, n. 1, p. 1-20, 1995.

BLANCHARD, O. Macroeconomia, 4a Edição, São Paulo: Prentice Hall, 2004. 
BOMFIM, C. STJ substitui prisão de irmãos Joesley e Wesley Batista por medidas cautelares. G1, 20 fev. 2018. Recuperado em 24 de janeiro, 2019 de https://g1.globo.com/politica/noticia/stjsubstitui-prisao-de-irmaos-joesley-e-wesley-batista-por-medidas-cautelares.ghtml.

BRONZATTO, T. Banco Central comunica indícios de crime da JBS. Revista Veja, 3 jun. 2017. Recuperado em 14 de janeiro, 2019 de https://veja.abril.com.br/economia/banco-centralcomunica-indicios-de-crime-da-jbs/

CNI. ICEI - Índice de Confiança do Empresário Industrial, ano 21, n. 12, dezembro 2019. Recuperado em 26 de maio, 2020 de http://www.portaldaindustria.com.br/estatisticas/iceiindice-de-confianca-do-empresario-industrial/

COSTA, A. C.; NARCIZO, B. Os reis do abate. Revista Veja, 24 maio 2017, Edição 2531, ano 50, no 21.

CVM. Cadernos CVM - 11. Uso Indevido de Informação Privilegiada (Insider Trading) / Comissão de Valores Mobiliários. Rio de Janeiro: Comissão de Valores Mobiliários, 2016. 45p.

EISENHARDT, K. M. Agency Theory: an assessment and review. Academy of Management Review, v. 14, n. 1, p. 57-74, 1989. DOI:10.2307/258191

FACCIO, M. Politically Connected Firms. The American Economic Review, 2006. v. 96, n. 1, p. 369-386. DOI:10.1257/000282806776157704

FAMA, E. Efficient Capital Markets: A Review of Theory and Empirical Work. Journal of Finance, v. 25 , n. 2, p. 383-417, 1970. DOI: 10.2307/2325486

FISMAN, R. Estimating the Value of Political Connections. The American Economic Review, v. 91, n. 4, p. 1095-1102, 2001. DOI:10.1257/aer.91.4.1095

GAIER, R. V. BNDES deve vender parcela de fatia na JBS em 2019, dizem fontes. Reuters, 11 dez. 2018. Recuperado em 20 de janeiro, 2019 de https://br.reuters.com/article/businessNews/idBRKBN1OA1QB-OBRBS.

GUNDLACH G. T.; ROOT A. R.; MURPHY P. E. Corporate Political Action: The Erosion of the Political Speech Doctrine. Journal of Business Research, v. 24, n. 4, p. 331-346, 1992.

DOI:10.1016/0148-2963(92)90038-D

GETZ, K. A. Research in Corporate Political Action. Business \& Society, v. 36, n. 1, p. 32-72, 1997. DOI:10.1177/000765039703600103

GRAHAM K. W. Corporate Political Strategies. British Journal of Political Science, v. 20, n. 2, p. 281-288, 1990. DOI:10.1017/S0007123400005822 
Relacionamento com o governo e informação privilegiada: o caso da JBS no mercado de capitais brasileiro

HILLMAN, A. J.; HITT, M. A. Corporate Political Strategy Formulation: A Model of Approach, Participation, and Strategy Decisions. Academy of Management Review, v. 24, n. 4, p. 825-842, 1999. DOI:10.5465/amr.1999.2553256

HILLMAN, A.; ZARDKOOHI, A.; BIERMAN, L. Corporate Political Strategies and Firm Performance: Indications of Firm-Specific Benefits from Personal Service in the U.S. Government. Strategic Management Journal, v. 20, n. 1, p. 67-81, 1999. DOI: 10.1002/(SICI)10970266(199901)20:1<67::AID-SMJ22>3.0.CO;2-T

HOLBURN, G. L. F.; ZELNER, B. A. Political capabilities, policy risk, and international investment strategy: Evidence from the global electric power generation industry. Strategic Management Journal, v. 31, n. 12, p. 1290-1315, 2010. DOI: 10.1002/smj.860

JBS. (2019). Website Institucional. Recuperado em 14 de janeiro, 2019 de https://jbs.com.br/sobre/historia/

JENSEN, M. C.; MECKLING, W. H. Theory of the firm: Managerial behavior, agency costs and ownership structure. Journal of Financial Economics, v. 3, n. 4, p. 305-360, 1976. DOI:10.1016/0304-405X(76)90026-X

JIMÉNEZ, C.; OLIVEIRA, R. Mercado dá adeus a reformas de Temer no curto prazo e prevê dias difíceis na economia. El País, 19 maio 2017. Recuperado em 22 de janeiro, 2019 de https://brasil.elpais.com/brasil/2017/05/18/economia/1495143459_395778.html.

LUCAS, R. E. Asset prices in an exchange economy. Econometrica, v. 46, n. 6, p. 1429-1446, 1978. DOI:10.2307/1913837

MARTINS, O. S.; PAULO, E.; ALBUQUERQUE, P. H. M. Negociação com informação privilegiada e retorno das ações na BM\&FBOVESPA. RAE - Revista de Administração de Empresas, v. 53, n. 4, p. 350-362, 2013. DOI:10.1590/S0034-75902013000400003

PROCIANOY, J. L.; ANTUNES, M. A. Os efeitos das decisões de investimento das firmas sobre os preços de suas ações no mercado de capitais. XXV ENANPAD, 25., Campinas. Anais [...]. Campinas: ANPAD, set. 2001. 15 p. Disponível em: http://www.anpad.org.br/admin/pdf/enanpad2001-fin-168.pdf. Acesso em 25 maio 2020.

PEREIRA, D.; RANGEL, R.; BONIN, R. À Beira do Abismo. Revista Veja, 24 maio 2017. Edição 2531, ano 50, no 21.

VEJA, Revista. Corrupção 7 X 1, 24 maio 2017, Edição 2531, ano 50, n. 21.

ROCHA, D. Crise política ameaça empresas que conseguiram reduzir dívidas. Revista Exame, 5 jun. 2017. Recuperado em 20 de janeiro, 2019 de https://exame.abril.com.br/revistaexame/crise-politica-ameaca-empresas-que-conseguiram-reduzir-dividas. 
Raul Beal Partyka, Bruno Bergmann e Rosilene Marcon

SALLES, A. A. Eficiência informacional do mercado futuro do lbovespa. In: XV ENANPAD, 15., Salvador. Anais [...]. Salvador: ANPAD, set. 1991. p. 151-164.

SARAIVA, A. Impacto da delação da JBS pode frear confiança da indústria, diz FGV. Valor Econômico, 22 maio 2017. Recuperado em 14 de janeiro de 2019 de https://www.valor.com.br/brasil/4976612/impacto-da-delacao-da-jbs-pode-frear-confianca-daindustria-diz-fgv

SILVEIRA, A. Di M. da. Governança corporativa no Brasil e no mundo: teoria e prática. 2. ed. Rio de Janeiro: Elsevier, 2015.

SHLEIFER, A.; VISHNY, R.W. A Survey of Corporate Governance. The Journal of Finance, v. 52, n. 2, p. 737-783, 1997. DOI:10.1111/j.1540-6261.1997.tb04820.x

STIGLITZ, J. E. The allocation role of the stock market: pareto optimality and competition. The Journal of Finance, v. 36, n. 2, p. 235-251, 1981.

TREVIZAN, K. Bovespa fecha na maior queda em quase 9 anos após denúncias da JBS. G1, 18 maio 2017. Recuperado em 14 de janeiro, 2019 de https://g1.globo.com/economia/mercados/noticia/bovespa-fecha-em-forte-queda-de-olho-emdenuncias-sobre-temer.ghtml

TRICKER, B. Corporate Governance: principles, policies and practices. 3. ed. Oxford: Oxford University Press, 2014.

VASSALLO, L.; AFFONSO, J.; MACEDO, F. CVM vê potencial de 'vantagem indevida' à JBS por vazamento de delação. O Estado de S. Paulo, 11 ago. 2017. Recuperado em 21 janeiro, 2019, de https://politica.estadao.com.br/blogs/fausto-macedo/cvm-ve-potencial-de-vantagem-indevidaa-jbs-por-vazamento-de-delacao.

ZALIS, P. Por que ele se deu tão bem. Revista Veja, 31 maio 2017. Edição 2532, ano 50, no 22. 